\title{
Manifestation of critical thinking skills in the English textbooks employed by language institutes in Iran
}

Birjandi, Parviz

Allame Tabatabai University, Iran (pbirjand@yahoo.com)

Alizadeh, Iman $\bowtie$

Allame Tabatabai University, Iran (iman_alizadeh87@yahoo.com)

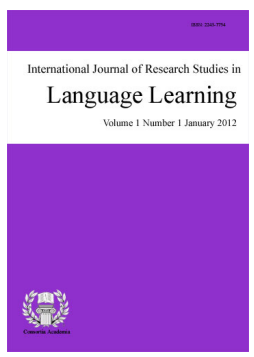

ISSN: 2243-7754 Online ISSN: 2243-7762

OPEN ACCESS

\section{Abstract}

Scholars in the field of education have unanimously subscribed to the pivotal role of critical thinking in individuals' life in general and their academic life in particular (Bloom, 1956; Ennis, 2003; Dewey, 1933). The thrust of the current study was to investigate the extent to which the books employed for Teaching English as Foreign Language include critical thinking skills. To attain this goal, 3 series of English books, namely, Top notch, Interchange, and English files series utilized by language institutes in Iran were targeted. Next, a seventy two-item critical thinking checklist based on Likert-scale and consisting of twelve skills; namely, comprehension, application, analysis, synthesis, evaluation, deduction, induction, balanced-thinking, multiple perspective-taking, creative thinking, building community of thinkers, and knowledge was developed. The target skills on the checklist were mainly based on Bloom's taxonomy and the related literature on critical thinking. The checklist was validated by the researchers themselves and some experts in the field and the reliability coefficient was also estimated at 0.86 . Then, two raters conducted a content analysis on the books and determined the magnitude of each skill. The data were analyzed through descriptive statistics and inferential statistics (Chi-square and Kruskal-Wallis Non-parametric tests). Findings of the study revealed that the books mainly tapped knowledge, comprehension, application and building community of thinkers skills and failed to acceptably include other skills reported to be of utmost importance for students' academic success. The comparison of the mean rank of the skills in the three books also disclosed that as for lower order thinking skills there wasn't a significant difference among the books; however, as for other skills Top notch was marginally higher. The paper also discusses the lack of critical thinking in the classroom and materials and proposes some ways to include more critical thinking skills in the materials. The results of the study have significant implications for material developers, educational policy makers and teachers.

Keywords: critical thinking skills; English books; Iran; language institutes 


\section{Manifestation of critical thinking skills in the English textbooks employed by language institutes in Iran}

\section{Introduction}

\subsection{Critical thinking}

It is axiomatic that all education systems aspire to prepare learners who consider issues or concepts, academic or general, through lenses different from that of nonprofessionals. Scholars and researchers in the field of education have generally reached the conclusion that an efficient way to this aim is encouraging education systems to invest in developing and fostering learners' critical thinking skills (See Implications for higher education (Zhang, 2009), Effects of dialogic learning on value-loaded critical thinking (Frijters, Dam, \& Rijlaarsdam, 2008), Peer interaction and critical thinking: Face-to-face or online discussion? (Guiller, Durndell, \& Ross, 2008). Reviewing the literature on critical thinking reveals a host of definitions of critical thinking. Epstein (2006) states that critical thinking involves evaluation, namely to be convinced that some claim is true or some argument is good; as well as, being able to formulate good arguments. Browne and Keeley (2007) believe that critical thinking consists of awareness of a set of interrelated critical questions, plus the ability and willingness to ask and answer them at appropriate times. Paul and Elder (2008) define critical thinking as the art of analyzing and evaluating thinking with a view to improving it. Halpern (2003) also states that the term critical thinking is used to describe thinking that is purposeful, reasoned and goal directed. It is the kind of thinking involved in solving problems, formulating inferences, calculating likelihoods, and making decisions. A more significant issue regarding critical thinking is its pivotal role in education. In this regard, Lipman (1988) asserts that the emphasis in education is shifting from the acquisition of facts to the process of thinking. The goal is to have students think for themselves.

Appealing and encouraging though the definitions seem in terms of the features they represent, the abilities included in these definitions do not lend themselves easily to handy gadgets to be utilized by individuals. In this regard, Paul and Elder (2006) claim that the development of critical thinking does not happen overnight. It is rather a long-term process taking up years to develop. They mention six stages through which critical thinking develop. These stages are as follows:

Stage 1: The Unreflective Thinker (we are not aware of significant problems in our thinking)

$>\quad$ Stage 2: The Challenged Thinker (we become aware of the problems in our thinking)

$>\quad$ Stage 3: The Beginning Thinker (we try to improve but without regular practice)

$>\quad$ Stage 4: The Practicing Thinker (we recognize the necessity of regular practice)

$>\quad$ Stage 5: The Advanced Thinker (we advance in accordance with our practice)

$>\quad$ Stage 6: The Master Thinker (skilled and insightful thinking become second nature to us)

Although the path of becoming a master thinker and thinking critically promises to be long and labyrinthine, measures have been taken to implant theses abilities in learners. For example, Halpern (2003) discusses the notion of explicit instruction in how to think. She asserts that although many authorities in higher education do not agree that college students should receive explicit instruction in how to think, when thinking skills are explicitly taught for transfer, using multiple examples from several disciplines, students can learn to improve how they think in ways that transfer across academic domains. To do so, a Four-Part Model for explicit teaching of critical thinking is proposed which is as follows:

$>\quad$ Part one: Dispositions for critical thinking: it explains that it is not enough to teach college students the skills of critical thinking if they are not inclined to use them. A disposition for critical thinking is to be present in the learners or is to be cultivated. 
Manifestation of critical thinking skills in the English textbooks employed by language institutes in Iran

$>$ Part two: Instruction in the skills: Critical thinking skills are to be instructed.

$>$ Part three: Structure training: a means of improving the probability that student will recognize when a particular thinking skill is needed, even in a novel context.

$>\quad$ Part four: Meta-cognitive monitoring. Meta-cognition is usually defined as what we know about what we know. Hence, meta-cognitive monitoring is determining how we can use this knowledge to direct and improve the thinking and learning process. While engaging in critical thinking, students need to monitor their thinking process, check that progress is being made toward an appropriate goal, ensure accuracy, and make decisions about the use of time and mental effort.

Moreover, Schafersman, (1991) proposes that there are generally two methods for teaching critical thinking. The first method, which is also the easiest, is to simply modify one's teaching and testing methods slightly to enhance critical thinking among one's students. This can be materialized through lectures, laboratories, homework, quantitative exercises, term papers and exams. The second method makes use of formal critical thinking exercises, programs, and materials that have been prepared by specialists and can be purchased for immediate use by the teacher or instructor.

\subsection{Textbook evaluation}

There are a host of elements influencing both English instructors and learners' performance in an EFL/ESL classroom. It is generally and frequently observed that the textbooks employed in the classrooms play a crucial role in the process of teaching and learning. Many scholars in the field have also emphasized the role of textbooks in classroom dynamics. For instance, Hutchinson and Torres (1994) suggest that "The textbook is an almost universal element of [English language] teaching. Millions of copies are sold every year, and numerous aid projects have been set up to produce them in [various] countries...No teaching-learning situation, it seems, is complete until it has its relevant textbook" (p. 315). Moreover, Sheldon (1988) suggests that textbooks not only represent the visible heart of any ELT program but also offer considerable advantages for both the student and the teacher when they are being used in the ESL/EFL classroom.

Reviewing the literature on textbook evaluation also reveals the advantages of textbooks in the processes of learning and teaching. For example, Haycroft (1998) suggests that one of the advantages of using textbooks is that they are psychologically essential for students since their progress and achievement can be measured concretely when we use them. O'Neill (1982) has indicated that textbooks are generally sensitive to students' needs, even if they are not designed specifically for them, they are efficient in terms of time and money, and they can and should allow for adaptation and improvisation. Sheldon (1988) has also pointed out that students often harbor expectations about using a textbook in their particular language classroom and program and believe that published materials have more credibility than teacher-generated or "in-house" materials. Additionally, textbooks yield a respectable return on investment, are relatively inexpensive and involve low lesson preparation time, whereas teacher-generated materials can be time, cost and quality defective. In this way, textbooks can reduce potential occupational overload and allow teachers the opportunity to spend their time undertaking more worthwhile pursuits (O'Neill, 1982; Sheldon, 1988). Furthermore, Hutchinson and Torres (1994) have pointed out that textbooks are key to innovation. They suggest that textbooks can support teachers through potentially disturbing and threatening change processes, demonstrate new and/or untried methodologies, introduce change gradually, and create scaffolding upon which teachers can build a more creative methodology of their own. Finally, Cunningsworth (1995) argues that textbooks are an effective resource for self-directed learning, an effective resource for presentation material, a source of ideas and activities, a reference source for students, a syllabus where they reflect pre-determined learning objectives, and support for less experienced teachers who have yet to gain in confidence.

Although many scholars in the field have commented on the positive points of employing textbooks in the classrooms, instructors and researchers in the opposition front have downgraded the commonly held views 
regarding textbooks. Allwright (1982), for instance, has commented scathingly on the employment of textbooks in the ELT classroom. He argues that textbooks are inordinately inflexible and are pedagogically, psychologically, and linguistically biased. Moreover, the educational methodology advanced by a textbook overshadows the mechanisms of classroom by indirectly implanting external language objectives and learning elements on students as well as different instructional models on the teachers. Therefore, textbooks implicitly or explicitly determine the methods, processes and procedures of language teaching and learning. Additionally, the pedagogic principles that are often displayed in many textbooks may also be incongruous or even old-fashioned depending on the interests and hidden agenda of the sponsoring agents.

Social and cultural biases have also been the target of many researchers. For example, Porreca (1984), Florent and Walter (1989), Clarke and Clarke (1990), Carrell and Korwitz (1994), and Renner (1997) have demonstrated that many EFL/ESL textbooks still contain examples of gender bias, sexism, and stereotyping. Other scholars have emphasized culture load of English textbooks. For example, Prodromou (1988) and Alptekin (1993) have focused on the use of the target language culture as a vehicle for teaching the language in textbooks and suggest that it is not really possible to teach a language without embedding it in its cultural base. Phillipson (1992) is also wary of the complex relationship between language textbooks and the target language. Gray (2000), on the other hand, has defended the socio-cultural components of many textbooks. He suggests that English language textbooks are actually ambassadorial cultural artifacts and that student should not only critically engage their textbooks but also view them as more than mere linguistic objects.

Despite the advantages and disadvantages of textbooks, teachers and researchers should do their best to gain the best from the textbooks to achieve the aims and objectives that have already been set in terms of learner needs. Therefore, we must make every effort to establish and apply a wide variety of relevant and contextually appropriate criteria for the evaluation of the textbooks that we use in our language classrooms. Sheldon (1988) has offered several other reasons for textbook evaluation. He suggests that a thorough evaluation would enable the managerial and teaching staff of a specific institution or organization to discriminate between all of the available textbooks on the market. Additionally, Cunningsworth (1995) and Ellis (1997) suggest that textbook evaluation helps teachers move beyond impressionistic assessments and it helps them to acquire useful, accurate, systematic, and contextual insights into the overall nature of textbook material.

There are a host of evaluation checklists based on different criteria that can be employed by teachers and researchers. In this regard, Cunningsworth (1995) and Ellis (1997) have suggested that there are three different types of material evaluation. They argue that the most common form is probably the 'predictive' or 'pre-use' evaluation that is designed to examine the future or potential performance of a textbook. The other types of textbook evaluation are the 'in-use' evaluation designed to examine material that is currently being used and the 'retrospective' or 'post-use' (reflective) evaluation of a textbook that has been used in any respective institution. As Sheldon (1988) suggests no general list of criteria can ever really be applied to all teaching and learning contexts without considerable modification. However, most evaluation checklists contain similar components that can be used as helpful starting points for ELT practitioners. Great figures in the field of ELT textbook design and analysis such as Williams (1983), Sheldon (1988), Brown (1995), Cunningsworth (1995) and Harmer (1996) all agree that evaluation checklists should include some criteria such as layout, organizational, and logistical characteristics of textbook's, methodology, aims, the specific language functions, grammar, the relevance of linguistic items to the prevailing socio-cultural environment.

\subsection{Text Book Evaluation in Iran}

A number of textbook evaluation studies have also been done in Iran. For example, Tavakoli (1995) used Searle's (1976) model of speech act to analyze dialogues excerpted from three English textbooks, used in Iran at the high school senior level, to see whether different forms of speech acts were correctly used and how frequently each function was used. The researcher concluded that only three of the five language functions, that is, representative, directive, and expressive, were introduced in the textbooks, while commissives and 
declarations were completely ignored. Besides, Darali (2007) studied the important features of new English textbooks such as the Spectrum series to see how cultural pragmatic knowledge of the language is included in the lessons. The results of the study showed that the series provided a variety of language functions, but the most frequent ones in daily speech were not focused on as much as other functions. Riazi and Aryasholouh (2007) also studied the four high school and pre-university English textbooks focusing on the consciousness-raising aspect of vocabulary exercises. They found that of all exercises in the four books, only one percent of them could be categorized as consciousness-raising. In another study, Jahangard (2007) evaluated four EFL textbooks that have been used in the Iranian high schools by the Ministry of Education. He discussed the merits and demerits of the textbooks with reference to 13 common criteria extracted from different materials evaluation checklists. The results of the study indicated that book four had better features in comparison with the three other textbooks.

This particular paper will report on a survey that focuses on the extent to which textbooks used in language institutes in Iran include critical thinking elements.

\subsection{Statement of the Problem and Purpose of the Study}

As mentioned, critical thinking is of utmost significance in education and learning. Critical thinking is now considered a factor which can cause individual, social, cultural, and scientific growth and development. However, stakeholders, in most educational settings, do not pay due attention to these skills because of traditional education system or lack of knowledge regarding these skills. The education system practiced in Iranian schools and private institutes is mainly based on transmitting information and limiting the learning to memorizing the materials. As a result, learners who grow in such systems rarely develop the capacity to think critically. The lack of critical thinking ability can be also due to the prescribed programs, being more product-oriented than process-oriented, the method of assessment and evaluation, and content of the textbooks which is the focus of the current study.

One of the factors which can play a significant role in fostering critical thinking in learners is enriching the materials presented to learners with these skills. This study aims at investigating the magnitude of critical thinking elements embedded in different English textbooks employed by different language institutes in Iran. The English textbooks investigated were Interchange Series, English File Series, and Top Notch Series. It is an attempt to discover the extent to which the English materials utilized at different institutes manifest critical thinking elements. Keeping the above-mentioned goals in mind the following questions were formulated:

Research Questions

1. Do the textbooks utilized present any of the elements of critical thinking?

2. What is the proportion of different critical thinking skills in different English textbooks?

3. What is the ranking of different English textbooks regarding critical thinking skills?

4. Is there a significant difference among the three textbooks regarding the inclusion of critical thinking skills?

\section{Method}

\subsection{Instrumentation}

The instrument employed in this study was a critical thinking checklist based on which two raters investigated the elements of critical thinking skills in the English textbooks employed by different institutes in Iran. 


\subsection{Procedure}

To achieve the goals of the study and answer the proposed questions, the incorporation of 12 critical thinking skills in three English textbooks, namely Interchange Series, English File Series, and Top Notch Series was studied. For the purpose of the study, firstly, a critical thinking checklist was developed. To develop the checklist, after studying the related literature on critical thinking, a pool of the most important and frequent criteria introduced as the constituent elements of critical thinking ability by distinguished figures in the field were listed. Further scrutiny and closer examination of the related literature revealed that frequent references had been made to Bloom's taxonomy. So the researchers decided to base their checklist on Bloom's taxonomy and add some other elements of critical thinking to make the checklist more comprehensive. These skills were: comprehension, application, analysis, synthesis, evaluation, deduction, induction, building community of thinkers, balanced-thinking, multiple perspective-taking, creative thinking, and knowledge. Next, the elements were operationalized, that is, for each skill 6 statements mirroring the characteristics of that skill were developed. Then, a range from 1 to 5 according to Likert scale was defined for each statement and the raters were asked to establish the size of these skills in the books based on the checklist. The checklist was validated by the researchers themselves and some experts and the reliability coefficient was also estimated as 0.86 .

\section{Findings}

To analyze the data collected through the checklist statistical tests and procedures like Kruskal-Wallis, Chi-square and cross tabulation were employed. In the following, you see the analysis of the data. In table 1, the status of each skill according to its incorporation in English textbooks is shown.

\section{Table 1}

The status of skills based on their incorporation in English textbooks

\begin{tabular}{|c|c|c|c|c|c|}
\hline \multirow{2}{*}{\multicolumn{2}{|c|}{ Critical Thinking Skills }} & \multicolumn{3}{|c|}{ Books } & \multirow{2}{*}{ Tota } \\
\hline & & Top Notch & Interchange & English files & \\
\hline \multirow{3}{*}{ Comprehension } & Good & 3 & 2 & 3 & 8 \\
\hline & Excellent & 9 & 10 & 9 & 28 \\
\hline & Total & 12 & 12 & 12 & 36 \\
\hline \multirow{5}{*}{ Application } & weak & 3 & 5 & 3 & 11 \\
\hline & Average & 2 & 4 & 4 & 10 \\
\hline & Good & 6 & 3 & 5 & 14 \\
\hline & Excellent & 1 & 0 & 0 & 1 \\
\hline & Total & 12 & 12 & 12 & 36 \\
\hline \multirow{5}{*}{ Analysis } & Not Applicable & 2 & 0 & 5 & 7 \\
\hline & Weak & 3 & 8 & 4 & 15 \\
\hline & Average & 4 & 3 & 2 & 9 \\
\hline & Good & 3 & 1 & 1 & 5 \\
\hline & Total & 12 & 12 & 12 & 36 \\
\hline \multirow{5}{*}{ Synthesis } & Not Applicable & 3 & 2 & 4 & 9 \\
\hline & Weak & 4 & 9 & 5 & 18 \\
\hline & Average & 3 & 0 & 2 & 5 \\
\hline & Good & 2 & 1 & 1 & 4 \\
\hline & Total & 12 & 12 & 12 & 36 \\
\hline
\end{tabular}


Manifestation of critical thinking skills in the English textbooks employed by language institutes in Iran

Table 1...continued

The status of skills based on their incorporation in English textbooks

\begin{tabular}{|c|c|c|c|c|c|}
\hline \multirow{2}{*}{\multicolumn{2}{|c|}{ Critical Thinking Skills }} & \multicolumn{3}{|c|}{ Books } & \multirow{3}{*}{$\begin{array}{c}\text { Total } \\
7\end{array}$} \\
\hline & & \multirow{2}{*}{$\frac{\text { Top Notch }}{0}$} & \multirow{2}{*}{$\frac{\text { Interchange }}{5}$} & \multirow{2}{*}{$\begin{array}{l}\text { English files } \\
2\end{array}$} & \\
\hline \multirow{5}{*}{ Evaluation } & Not Applicable & & & & \\
\hline & Weak & 2 & 7 & 5 & 14 \\
\hline & Average & 9 & 0 & 4 & 13 \\
\hline & Good & 1 & 0 & 1 & 2 \\
\hline & Total & 12 & 12 & 12 & 36 \\
\hline \multirow{6}{*}{ Deduction } & Not Applicable & 0 & 3 & 6 & 9 \\
\hline & Weak & 7 & 6 & 3 & 18 \\
\hline & Average & 1 & 3 & 2 & 4 \\
\hline & Good & 2 & 0 & 1 & 3 \\
\hline & Excellent & 2 & 0 & 0 & 2 \\
\hline & Total & 12 & 12 & 12 & 36 \\
\hline \multirow{4}{*}{ Balance Thinking } & Not Applicable & 8 & 7 & 8 & 21 \\
\hline & Weak & 1 & 4 & 3 & 11 \\
\hline & Average & 3 & 1 & 1 & 4 \\
\hline & Total & 12 & 12 & 12 & 36 \\
\hline \multirow{4}{*}{ Multiple Perspective } & Not Applicable & 8 & 7 & 8 & 20 \\
\hline & Weak & 2 & 4 & 2 & 11 \\
\hline & Average & 2 & 1 & 2 & 5 \\
\hline & Total & 12 & 12 & 12 & 36 \\
\hline \multirow{5}{*}{ Creative Thinking } & Not Applicable & 0 & 3 & 0 & 3 \\
\hline & Weak & 3 & 7 & 3 & 15 \\
\hline & Average & 4 & 2 & 5 & 11 \\
\hline & Good & 5 & 0 & 4 & 7 \\
\hline & Total & 12 & 12 & 12 & 36 \\
\hline \multirow{5}{*}{ Induction } & Not Applicable & 0 & 2 & 3 & 5 \\
\hline & Weak & 2 & 5 & 2 & 9 \\
\hline & Average & 6 & 2 & 3 & 11 \\
\hline & Good & 4 & 3 & 4 & 11 \\
\hline & Total & 12 & 12 & 12 & 36 \\
\hline \multirow{4}{*}{ Knowledge } & Weak & 6 & 4 & 5 & 15 \\
\hline & Average & 3 & 3 & 2 & 8 \\
\hline & Good & 3 & 5 & 5 & 13 \\
\hline & Total & 12 & 12 & 12 & 36 \\
\hline \multirow{5}{*}{ Community Thinkers } & Weak & 0 & 2 & 1 & 3 \\
\hline & Average & 4 & 4 & 5 & 13 \\
\hline & Good & 7 & 6 & 6 & 19 \\
\hline & Excellent & 1 & 0 & 0 & 1 \\
\hline & Total & 12 & 12 & 12 & 36 \\
\hline
\end{tabular}

According to the obtained data, it can be judged that the magnitude of Comprehension, Application, Community Thinkers and Knowledge skills was virtually satisfactory; Creative Thinking, Analysis, Synthesis and Deduction skills were sparsely embedded in the books; Evaluation, and Induction skills were weakly tapped, and Multiple Perspective-Taking, and Balanced thinking were hardly touched. 
Birjandi, P. \& Alizadeh, I.

Table 2

Ranks of the Three Books According to the CTS

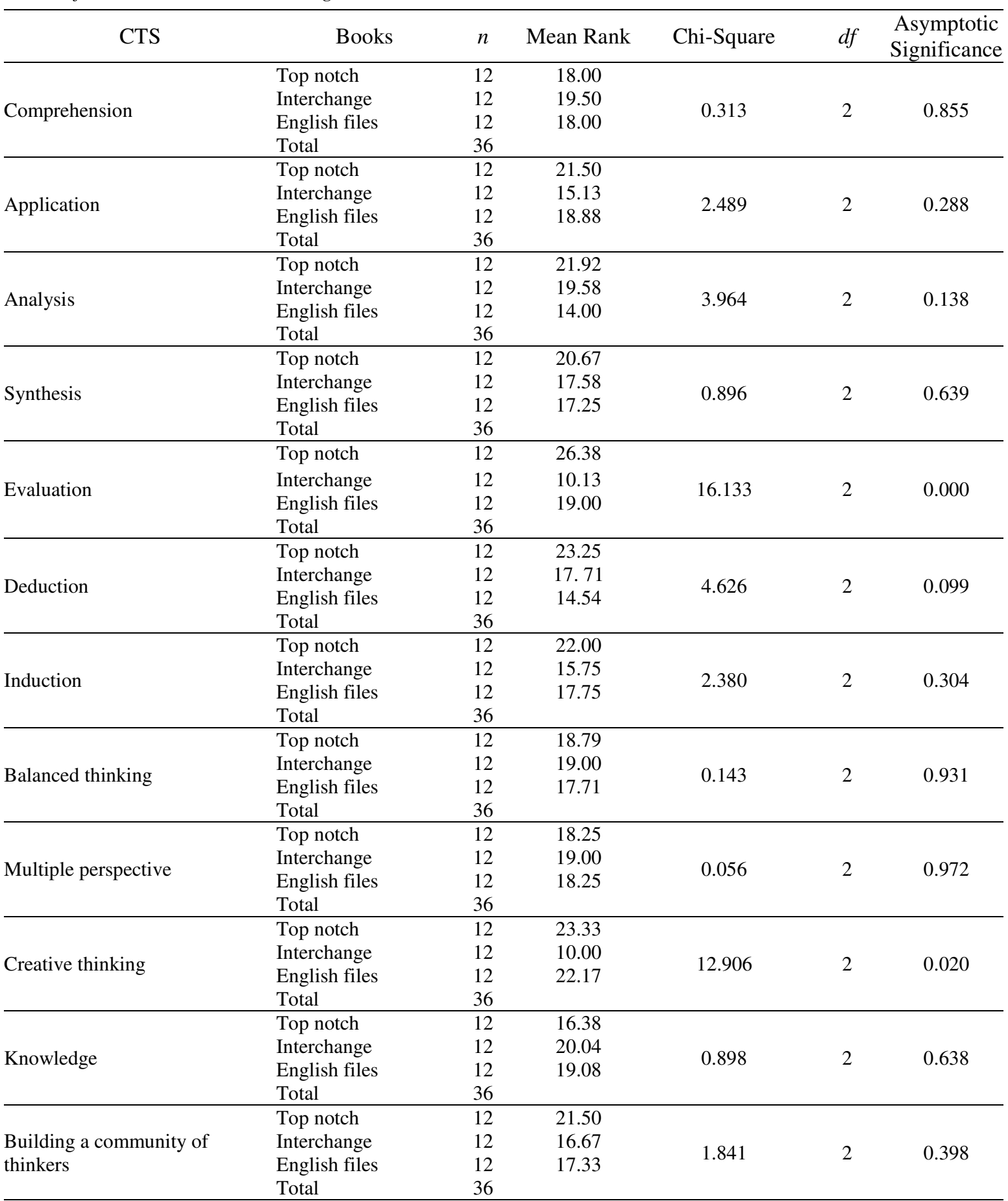

Table 2 shows the results of non-parametric Kruskal-Wallis test. According to the values obtained, it is understood that, at the level of .05, the average of comprehension, application, analysis, synthesis, deduction, induction, balanced-thinking, multiple perspective-taking, and knowledge skills in the books is almost the same. Therefore, it can be concluded that at the level of .05 these books have almost the same status. However, the hypothesis about the equality of the amount of evaluation, and creative thinking skills is rejected at the .05 level, which indicates that the average use of these skills in the books is not the same. 


\section{Discussion}

According to the findings of the study, it can be safely claimed that the books mainly tapped comprehension and knowledge skills which are generally considered lower critically thinking abilities. The knowledge skill, as the name speaks, mainly requires recollecting data or information. As for this skill, the learners are asked to reproduce the load of information from memory to the teacher by matching, stating and selecting the items. Activities targeting this ability in the three books were asking learners to fill in the blanks with appropriate words and match the items. The analysis of the data revealed that the magnitude of this skill was strong and excellent in the three books. The mean rank of Interchange series was marginally higher than the two other textbooks, although there was not a significant difference at the 0.05 significance level. The comprehension skill, which is one level higher than knowledge skill, mainly includes a pool of skills such as understanding, translating, and paraphrasing the concepts at hand. This skill was tapped in the books by asking learners to answer the reading comprehensions questions or listening comprehension questions. Again, although there was no significant difference among the mean rank of the three books, Interchange series ranked the highest of all. According to the finding of the study it can be claimed that the ranking of the three books regarding these two skills was excellent. However, one should keep in mind that they are the only superficial or survival skills that are generally required to handle every concept.

All learned skills to be useful should be put into practice. As a critical thinking skill, the application skill requires materializing the blueprint in the mind. It also obliges learners to apply what is learned in the classroom milieu to novel real life situations. The findings of the study indicated that this skill had been moderately touched in the three books. Moreover, the results of the analysis showed that although Top notch, English files and Interchange series ranked first, second and third respectively, there was not a significant difference among the three books regarding the inclusion of this skill. As in the process of language learning learners should make use of, manipulate, modify, produce and regenerate the learned concepts in novel though artificial situations communicatively, more attention is to be paid to this skill. The current trend in ELT also calls for fostering communicative ability of learners which requires putting into practice the learned concepts and converting the concepts into action plans. The findings revealed that the difference among the books is not significant, and the overall size of this skill is not satisfactory and needs nourishing. To enrich the books in this skill, material developers can implant questions, tasks, activities and exercises which require learners to relate the concepts in the book to their context of learning and personal life. These tasks can be role play, simulation, developing portfolios and writing journals. These activities help students to materialize the ideas in their mind, identify genuine problems, and take constructive measures to solve the problems.

The next two skills investigated in the three books were analysis and synthesis. Analysis, according to Bloom (1956), mainly refers to breaking down material or concepts into component parts in order to detect the relationship among the parts, or the parts and the whole. It also includes comparing, contrasting, discriminating, and distinguishing the ideas. Bloom (1956) defines synthesis, on the other hand, as putting parts together to form a whole. It aims at building up or connecting separate pieces of information to form a larger, more coherent pattern. As the findings of the study showed, these books sparsely trigger these skills in learners. The results of the Kruskal Wallis test revealed that Topnotch, Interchange and English files ranked first, second and third respectively. However, the results did not signal a significant difference. The findings also indicate that due attention has not been paid to these skills which unlike knowledge and comprehension are higher critical thinking skills.

To improve the quality of these books with regard to these skills, as for analysis, material developers can include questions in the books which require learners to identify the underlying causes or sources of the issue at hand. They can also include activities that ask learners to prioritize the most important ideas included in the reading or discussed in the conversation or introduced in the listening section. Moreover, tasks can be developed for deconstructing the implicit or hidden agenda in the texts, quotes and listening sections. Besides, activities can be devised to push learners to compare and contrast ideas, customs and different concepts discussed in the books. 
As for synthesis, the opposite of what is done for analysis can be done. For example, jigsaw tasks could be developed in order to reorganize or rearrange and integrate the pieces of information to produce a more comprehensive understanding of the idea at hand. Moreover, concept mapping technique can be introduced to connect related ideas discussed in separate sections of a unit or the units of a book into a single, unified product.

One of the byproducts of education is training learners who do not take all inputs for granted. The skill mirroring this ability is evaluation skill. It, according to Bloom (1956), generally refers to making judgments about or appraising critically the value of concepts and data. The findings showed that this skill was weakly tapped in the books. However, the difference among the books was significant. As for this skill, Top notch ranked first, English files second and Interchange series third. Despite the significant and pivotal role of this skill in learners' academic and personal life, the magnitude of this skill in the three books was low and even lower than analysis and synthesis skills. To improve the quality of the books regarding this skill, tasks that require learners to evaluate the strengths and weaknesses of an argument are to be targeted. For example, materials can include questions that target the topic sentence of a paragraph and ask learners to evaluate how well it is supported in the reading text or the concluding sentence of an article can be employed for this purpose. Moreover, books can include some pictures and ask learners to rate the quality of the picture, evaluate the message conveyed by the picture and appraise the match between the message and the picture. Besides, some problems can be proposed requiring learners to propose solutions, evaluate the solutions and propose alternative solutions.

Deduction and induction also were the skills that were the target of the study. Deduction mainly refers to moving from general principles to particular instances. Induction is the opposite. It is moving from instances to general rules. The findings of the study showed that these skills were differently treated in the three books. The induction skill was weakly included in the three books. Nevertheless, the deduction skill was moderately encouraged by the books. As for the ranking of the books, Top notch was first in both skills, Interchange was second in deduction and third in induction and English file series was second in induction and third in deduction. As a solution for improving the size of these skills in the books more deduction / inductions questions can be included in the reading comprehension or listening comprehension sections. Moreover, deduction / inductions puzzles and games can be included in the books.

Balanced thinking and multiple perspective-taking were also studied as critical thinking skills in the current study. Balanced Thinking requires meticulous examination of the arguments for and against a particular concept. Multiple Perspective-Taking is viewing an issue from a variety of viewpoints or positions. These two skills were hardly included in the books. These two skills are highly important, as learners should consider the pros and cons, weaknesses and strengths of a concept to digest it well and formulate arguments that are reasonable. Despite the importance of these skills, only a few instances of these skills were observed in the books. To inject these skills in the materials, as for balanced thinking, material developers can devise questions in the reading comprehension part that require learners to list the evidence that supports and contradicts an idea or line of reasoning in the reading passages. As for multiple perspective-taking, questions requiring learners to consider the perspectives of other learners and the people from different racial groups or social classes can be included in discussion, reading, and writing parts. Moreover, there can be some passages from the perspective of different genders and the positions or views of the opposite gender can be inquired.

Creative thinking, as a critical thinking skill, was targeted as the ability to devise innovative strategies, or novel solutions in this study. This skill was also sparsely tapped in the books. The results of the analysis revealed that there was a significant difference among the three books regarding the inclusion of this skill. In this skill, Top notch, English files and Interchange series ranked first, second and third respectively. In order to foster this skill in learners, books can include tasks that require learners to devise metaphors or analogies for the concepts discussed in the reading comprehension, conversation and listening section. Moreover, learners can be asked to creatively find solutions or build strategies to the problems proposed by teachers or their classmates.

Building community of thinkers was another critical thinking skill that was investigated in the present study. 
Manifestation of critical thinking skills in the English textbooks employed by language institutes in Iran

It refers to an activity which learners put their heads together and devises methods for solving problems. It is somehow a problem solving which is based on group work. The findings showed that the three books functioned satisfactorily in this regard.

\section{Conclusion}

The current study aimed at investigating critical thinking skills in three English textbooks employed in language institutes in Iran. The overall findings of this study demonstrated that among the critical thinking skills investigated in the study comprehension, knowledge, application and community of thinkers were satisfactorily treated in the three books and the ranking of the three books regarding these skills was marginally but not significantly different. Induction and deduction were treated differently in the three books: Top notch was first in both skills, Interchange was second in deduction and third in induction and English file series was second in induction and third in deduction. The inclusion of induction was weak and deduction was moderate. Evaluation, balanced thinking, multiple-perspective taking skills were hardly or weakly included or encouraged in the books. There was no significant difference regarding the ranking of the books. However, Top notch was marginally higher in these skills. Analysis and synthesis skills were sparsely embedded in the three books. Although there was no significant difference among the books, Top notch again ranked marginally higher. The size of creative thinking was different, but low, in the three books. As for this skill, Top notch ranked first, English files second and Interchange series third.

Generally the inclusion of the skills in the three books can be grouped as satisfactory (comprehension, knowledge, application and community of thinkers), moderate to low (deduction, Analysis, and synthesis) and weak (Evaluation, balanced thinking, multiple-perspective taking, and creative thinking). As for the ranking of the books, it can be claimed that in the lower order thinking or cognitive abilities such as knowledge, comprehension application and community of thinkers the three books were almost the same. For the rest of the skills, although the inclusion was low and weak, Top notch mainly ranked first, English files ranked second and Interchange ranked third.

Findings of this study may offer instructors, educational administrators, syllabus designers, curriculum planners, and material developers some handy hints on the inclusion of critical thinking skills in the EFL materials. Different sections of the textbooks can be modified, some sections can be added, and exercises and tasks can be devised that step beyond the lower-order thinking skills introduced and investigated in this study to include higher-order skills in order to improve the quality of the books in this regard. Teachers can also employ the findings of the study and implant innovative techniques to their teaching methods to compensate for the weak points of the textbooks.

\section{References:}

Allwright, R. (1982). What do we want teaching materials for? ELT Journal, 36(1), 5-8.

$<$ http://dx.doi.org/10.1093/elt/36.1.5>

Alptekin, C. (1993). Target-language culture in EFL materials. ELT Journal, 47(2), 136-143. $<$ http://dx.doi.org/10.1093/elt/47.2.136>

Bloom, B. C. (1956). Taxonomy of educational objectives: Cognitive domain. New York: David McKay.

Browne, M. N., \& Keeley, S. M. (2007). Asking the right questions: to critical thinking. New Jersey: Pearson Education.

Carrell, D., \& Korwitz, J. (1994). Using concordancing techniques to study gender stereotyping in ELT textbooks. In J. Sunderland (Ed.), Exploring gender: Questions and implications for English language education. Prentice Hall International.

Clarke, J., \& Clarke, M. (1990). Stereotyping in TESOL materials. In B. Harrison (Ed.), Culture and the language classroom. ELT Documents. Modern English Publications/British Council.

Cunningsworth, A. (1995). Choosing your course-book. Heinemann. 
Birjandi, P. \& Alizadeh, I.

Darali, G. (2007). Pragmatics dimension in Spectrum textbooks. Unpublished master's thesis, Shiraz University, Iran.

Dewey, J. (1933). How we think. Boston: D.C. Heath and Company.

Ellis, R. (1997). The empirical evaluation of language teaching materials. ELT Journal, 51(1), 36-42. $<$ http://dx.doi.org/10.1093/elt/51.1.36>

Ennis, R. H. (2003). Critical thinking assessment. In Fasko, Critical thinking and reasoning: Current research, theory, and practice.

Epstein, R. L. (2006). Critical thinking. California: Wadsworth Thomas Learning.

Florent, J., \& Walter, C. (1989). A better role for women in TEFL. ELT Journal, 43(3), 180-184. $<$ http://dx.doi.org/10.1093/elt/43.3.180>

Frijters, S., Ten Dam, G., \& Rijlaarsdam, G. (2008). Effects of dialogic learning on value-loaded critical thinking. Learning \& Instruction, 18, 66-82. <http://dx.doi.org/10.1016/j.learninstruc.2006.11.001>

Grey, J. ( 2000). The ELT Course book as Cultural Artifact. ELT Journal, 54(3), 78-90.

Guiller, J., Durndell, A., \& Ross, A. (2008). Peer interaction and critical thinking: Face-to-face or online discussion? Learning and Instruction, 18, 187-200. <http://dx.doi.org/10.1016/j.learninstruc.2007.03.001>

Harmer, J. (1996). The practice of English language teaching. London: Longman.

Haycroft, J. (1998). An introduction to English language teaching. London: Longman.

Halpern, D. F. (2003). Thought and knowledge: An introduction to critical thinking (4th ed.). New Jersey: Erlbaum, Mahwah.

Hutchinson, T., \& E. Torres. (1994). The textbook as agent of change. ELT Journal, 48(4), 315-328. $<$ http://dx.doi.org/10.1093/elt/48.4.315>

Jahangard, A. (2007). The evaluation of the EFL materials taught at Iranian public high schools. Karen's Linguistics Issues. Retrieved October 2011 from: http://www3.telus.net/linguisticsissues/bymonth.html Lipman, M. (1984). The cultivation of reasoning through philosophy. Educational leadership, 42(1), 51-56. >O'Neill, R. (1982). Why use textbooks? ELT Journal, 36(2), 104-111. < http://dx.doi.org/10.1093/elt/36.2.104

Paul , R., \& Elder, L. (2006). Critical thinking: Tools for taking charge of your learning and your life (2nd ed.). NJ: Pearson Prentice Hall.

Paul, R. \& Elder, L. (1997). A brief history of the idea of critical thinking. Retrieved June 15, 2006, from http://www.crticialthinking.org/aboutCT/briefHistroyCT.cfm

Phillipson, R. (1992). Linguistic imperialism. Oxford University Press.

Porecca, K. (1984). Sexism in current ESL textbooks. TESOL Quarterly, 18(4), 70-24.

Prodromou, L. (1988). English as cultural action. ELT Journal, 42(2), 73-83. $<$ http://dx.doi.org/10.1093/elt/42.2.73>

Renner, C. (1997). Women are busy, tall, and beautiful: Looking at sexism in EFL materials. Annual Meeting of the Teachers of English to Speakers of Other Languages. Orlando, March 11-15.

Riazi, A. M., \& Aryashokouh, A. (2007). Lexis in English textbooks in Iran: Analysis of exercises and proposals for consciousness-raising activities. Pacific Association of Applied Linguists, 11, 17-34.

Schafersman, S. D. (1991). An introduction to critical thinking. Retrieved January 8, 2011, from http://www.freeinquiry.com/critical-thinking.html

Sheldon, L. (1988). Evaluating ELT textbooks and materials. ELT Journal, 42(2), 237-246. $<$ http://dx.doi.org/10.1093/elt/42.4.237>

Tavakoli, F. (1995). Functional analysis of the dialogues in the Iranian senior high school English textbooks. Unpublished master's thesis. Allameh University, Tehran.

Williams, D. (1983). Developing criteria for textbook evaluation. ELT Journal, 37(3), 251-261. $<$ http://dx.doi.org/10.1093/elt/37.3.251>

Zhang, L. F. (2009). From conceptions of effective teachers to styles of teaching: Implications for higher education. Learning and Individual Differences, 19, 113-118. <http://dx.doi.org/10.1016/j.lindif.2008.01.004> 